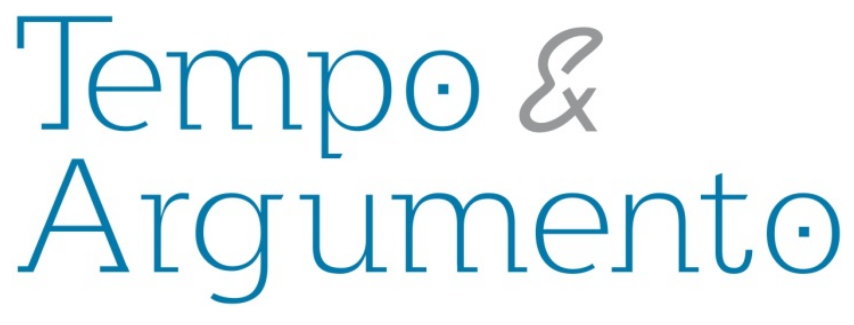

\title{
Carandiru: os usos da memória de um massacre ${ }^{1}$
}

\section{Resumo}

O massacre do Carandiru, ocorrido em 1992, é caracterizado como um marco simbólico na história do sistema penal brasileiro. A rememoração desse passado dialoga com questões como a dimensão do ocorrido, a impunidade, a tentativa de apagamento e conformação da memória e a instituição do massacre como metáfora para novas tragédias. Nesse processo é possível observar a construção de dois passados possíveis: um empreendido pelo Estado, instituindo uma memória oficial, e outro ligado a diferentes segmentos da sociedade civil organizada. Analisarei os usos dessa memória e suas estratégias de rememoração, categorias estas entendidas a partir da história do tempo presente e da história pública.

Palavras-chave: Carandiru; Memória; História Pública; História do Tempo Presente.

\section{Viviane Trindade Borges}

Doutora em História Universidade Federal do Rio Grande do Sul. Professora do Programa de PósGraduação em História da Universidade do Estado de Santa Catarina. Brasil

vivianetborges@gmail.com

\section{Para citar este artigo:}

BORGES, Viviane Trindade. Carandiru: os usos da memória de um massacre. Revista Tempo e Argumento, Florianópolis, v. 8, n. 19, p. 04 - 33. set./dez. 2016.

\section{DOI: $10.5965 / 2175180308192016004$}

http://dx.doi.org/10.5965/2175180308192016004

\footnotetext{
${ }^{1}$ Pesquisa com apoio do CNPq, Edital Universal 443433/2014-3.
} 


\begin{abstract}
Carandiru's massacre, occurred in 1992, is a symbol in Brazilian criminal justice system. Recalling this episode establishes a dialogue with affairs like its dimensions, impunity, attempts to erase and settle for memories, and institution of massacre as a metaphor to other tragedies like this. In this process it's possible to see the construction of two possible pasts: one which is made by the state, creating an official memory, and the other linked to parts of organized civil society. Examine the uses of memory and recall their strategies, these categories understood in from the history of this time and public history.
\end{abstract}

Keywords: Carandiru; Memory; Public History; History of the Present Time.

\title{
Usos da memória: entre a história do tempo presente e a história pública
}

Em 2 de outubro de 1992, a Polícia Militar de São Paulo invadiu a penitenciária do Carandiru para reprimir uma rebelião. A ação matou 111 presos em meia hora. As fotos dos corpos, nus e enfileirados no chão de concreto, correram o mundo como um símbolo da barbárie brasileira.

O massacre também se tornou sinônimo de impunidade. Depois de 24 anos, nenhum policial foi preso. Autoridades da época, como o governador Luiz Antônio Fleury Filho, nem chegaram a ser processadas. Agora o caso ganha mais um capítulo vergonhoso. O Tribunal de Justiça anulou os julgamentos que condenaram 74 PMs. Todos recorriam em liberdade, apesar da gravidade dos crimes e das penas de até 624 anos de prisão.

O relator do recurso, desembargador Ivan Sartori, defendeu a absolvição dos PMs. Ao justificar o voto, ele tentou reescrever a história. "Não houve massacre, houve legítima defesa", afirmou. A declaração é espantosa porque as vítimas estavam desarmadas e todos os policiais saíram vivos. A perícia contou uma média de cinco tiros por corpo, muitos disparados pelas costas e na cabeça².

\footnotetext{
${ }^{2}<$ http://www1.folha.uol.com.br/colunas/bernardomellofranco/2016/og/1817475-a-nova-vergonha-docarandiru.shtml >. Acessado em: 12/01/2015.
} 
A reportagem em questão, do colunista político Bernardo Mello Franco, publicada na Folha de São Paulo, jornal de grande cirulação nacional e, portanto, agente social fundamental na história do presente, data de 28 de setembro de 2016 e mostra a contemporaneidade de um episódio do sistema penal ocorrido há 24 anos. Logo após a divulgação da notícia, vários memes tomaram conta das redes sociais brasileiras: fotografias do massacre acompanhadas da frase "Não esquecemos" e outros que mostravam dados estatísticos que contradizem a afirmação de legítima desfesa, como o fato de 90,4\% das vítimas terem sido alvejadas na cabeça e pescoço. Além de manifestações como uma Nota Pública do Instituto Brasileiro de Ciências Criminais, questionando a decisão ${ }^{3}$. Essas reivindicações foram disseminadas rapidamente, em um movimento de reinvenção constante, perpassado por novas imagens e novas frases que se transmutam incessantemente. Nesse fluxo, o acontecimento é legitimado enquanto responsabilidade do Estado, um discurso que se enuncia não como versão, mas como "verdade".

Existem muitas maneiras de lidar com o passado e todas elas envolvem conflitos, interesses, relações de poder, apagamentos e exclusões. Rememorar o passado, selecionar dele o que deve ser lembrando, não é algo natual, mas um processo que envolve seleção. A história do massacre do Carandiru tornou-se uma questão pública, uma história movediça, em pleno desenrolar, escrita através de uma profusão de materiais que a divulgam para um público cada vez mais amplo, atendendo as demandas sociais que desejam discutir o ocorrido. Uma história pública institucionalizada e não institucionalizada, mas produzida e compartilhada em uma gama de configurações tecida por profissionais e não profissionais.

A história que cerca o Carandiru ganhou reprecussão nacional e internacional. Lugar de bandidos, assaltantes, assassinos, presos políticos e traficantes. Local da maior tragédia prisional do país. Como lidar com um passado marcado por uma história trágica, que desvela a degradação humana? Demolir, varrer do tecido urbano esses marcos simbólicos permite apagar esse passado?

\footnotetext{
${ }^{3}<$ http://www.ibccrim.org.br/destaques/229-Nota-Publica>. Acessado em 14/11/2016.
} 
Analisarei aqui uma trama marcada por disputas, problematizando os usos da memória do massacre, envolvendo políticas de memória ligadas à história do tempo presente e debates oriundos das possibilidades da história pública do massacre. Prentendo cotejar a vasta produção cultural que constantemente reatualiza as memórias sobre esse passado que não passa e a maneira como ela se confronta, se articula e se interpela com as estratégias de apagamento e/ou apaziguamento dessa história de horrores, percebendo as ressonâncias e a complexidade desses enfrentamentos em diferentes segmentos sociais, os quais também atuam nas suas ressignificações.

Para isso, farei uso de categorias fundamentais para a história do tempo presente e para a história pública, focando nos usos da memória e na sua relação com as demandas sociais $^{4}$. A História do Tempo Presente ${ }^{5}$ remete à França, ao Instituto de História do Tempo Presente (IHTP), criado entre 1978 e 1980. Sob esta perspectiva, temas há muito trabalhados pela história, como aqueles ligados à memória, ganham novas significações quando cotejados a partir de questões acerca do passado recente e/ou da maneira como esse passado vem sendo reconfigurado, entendido e/ou experimentado (VARELA, et al., 2012).

$\mathrm{Na}$ atualidade, podemos observar a hegemonia da memória entendida como um “valor", por vezes oposto à história, o qual resulta em uma vontade da sociedade de agir sobre o passado, repará-lo, rejulgá-lo (ROUSSO, 2007). Questões mais amplas como aquelas ligadas aos usos da memória tornam-se alegóricas quando se referem a traumas e tragédias recentes e às demandas sociais que perpassam a história do tempo presente.

\footnotetext{
${ }^{4}$ Outras categorias interligam história do tempo presente e a história pública, aqui não entendias como genêros historiográficos, mas sim como propostas que provocariam debates e enfrentamentos no campo da história, tais como o papel dos historiadores frente aos debates públicos e suas reverberações sociais, políticas e culturais. Bem como as possíveis apropriações da história por diferentes públicos e a produção histórica e suas múltiplas linguagens. Centrarei aqui apenas nas questões dos usos da memória. Sem pretender esgotar o tema, a respeito da História do Tempo Presente ver: (BÉDARIDA, 1993), (CHAVEAU; TÉTART, 1999), (LAGROU, 1999), (ROUSSO, 2007), (RICOEUR, 2011), (DOSSE, 2012). Da mesma forma, a respeito da História Pública ver: (CAUVIN, 2016), (GROOT, 2016).

${ }^{5} \mathrm{Na}$ América Latina, a discussão vem se consolidando através de instituições preocupadas em dedicar pesquisas voltadas à História do Tempre Presente, entendendo esta como um campo de estudo, como a Universidade de la Republica de (Montevideo), na Argentina, a Universidade de los Andes, na Colômbia, e Universidade do Estado de Santa Catarina, no Brasil. A partir disso, temos uma série de publicações sobre o tema na América Latina. Sem pretender esgotar o tema, ver: (FERREIRA, 2002), (SARLO, 2001), (MARQUES et al, 2003), (PORTO, 2007), (VENGOA, 2010), (BRESCIANO, 2010), (FERREIRA 2010), (VARELA, 2012), (DELGADO, FERREIRA, 2014).
} 
A História Pública, nascida em países como Estados Unidos, Inglaterra e Austrália, também se debruça sobre estas questões, atuando como um

guarda-chuva conceitual capaz de abrigar tudo aquilo que tem sido pensado e escrito como: usos da memória; usos do passado; demanda social; percepção pública da história; divulgação científica da história; interpretação e curadoria; empoderamento e pesquisa-ação; apropriações midiáticas, literárias e artíticas da história e assim por diante (SANTHIAGO, 2016, p. 26).

A história pública seria um espaço para a consolidação de um debate, um esforço em pensar esses temas a partir de uma noção de fazer a história com e para os sujeitos e grupos pesquisados e a maneira como esses grupos estão contando as histórias que consideram importantes, entendendo que a prática histórica não se limita aos ambientes acadêmicos. A história pública procura expor o uso de habilidades históricas fora do âmbito acadêmico tradicional da história, alcançando grupos não especializados através de diversos meios, como exposições, locais históricos, apresentações de audiovisual, jogos, sites, entre outros (CAUVIN, 2016) ${ }^{6}$.

Tratar de temas contemporâneos é lidar com a crítica em relação à ausência de recuo, exigindo do pesquisador uma dose de cuidado para tecer os instrumentos necessários para sua análise crítica. Nessa teia, o historiador é também agente ativo nos embates trazidos pelas demandas sociais, apreendendo uma história em pleno desenrolar dos fatos, contemporâneo do objeto que pretende analisar, partilhando com aqueles cuja história anseia narrar categorias essenciais muito próximas, bem como as mesmas referências fundamentais (CHARTIER, 2000, p. 215-218).

\footnotetext{
${ }^{6}$ No Brasil, esse campo vem se consolidando desde 2011 quando foi criada a Rede Brasileira de História Pública, com a realização de encontros e publicações (MAUAD et al, 2016) (ALMEIDA e ROVAI, 2011). A International Federation for Public History existe desde 2010 e também tem realizado encontros internacionais sobre o tema. Na América Latina, o grande número de trabalhos apresentados por pesquisadores latino-americanos no último encontro internacional ocorrido, em Bogotá, na Colômbia, em 2016, revela a emergência do tema. A esse respeito ver: <https://faciso.uniandes.edu.co/images/Documentos/3rdInternationalPublicHistoryConference.pdf $>$. Acessado em 15/11/2016.
} 
A noção de tempo presente permite a revisitação do passado e de suas possíveis certezas e incertezas. O conceito de "tempo presente" remete "ao que é do passado e nos é ainda contemporâneo, ou ainda, apresenta um sentido para nós do contemporâneo não contemporâneo" (DOSSE, 2012, p. 11). A história do massacre do Carandiru é um tema político complexo, um debate público, um passado próximo que ainda nos é muito atual.

Os usos do passado se inserem em uma construção de sentidos conflituosa, permeada por disputas de memória, seleção, esquecimentos e demandas sociais. A história do tempo presente foi arrebatada por um verdadeiro surto memorialístico, uma cultura da memória (HUYSSEN, 2000) que se alastrou inclusive pelos espaços e pelas experiências ligadas ao sofrimento e ao trauma. Esses locais parecem constantemente estreitar a distância entre passado e presente, possibilitando que as futuras gerações relembrem tragédias que não vivenciaram. Nessa tessitura, é possível obervar um esforço em torno do ato de recordar, preservar, rememorar, frente ao iminente risco de esquecimento.

Existe uma contradição inerente aos processos de rememoração, envolvendo obrigatoriamente seleção e esquecimento. A memória é resultado de um processo de interação social; ela tanto está em nós quanto é exterior a nós (SANTOS, 2007). Os discursos estão inscritos em relações de poder circulares, que se apoiam, mas também se afastam e se interpelam. O que lembrar e para quem lembrar são questões importantes a serem problematizadas quando pensamos nos usos da memória. "A elaboração da memória se dá no presente e para responder a solicitações do presente. É do presente, sim, que a rememoração recebe incentivo, tanto quanto as condições para se efetivar" (MENESES, 1992, p. 11). É no presente que esse passado trágico vem sendo sistematicamente resignificado. A tragédia segue ecoando no social e dialoga com condições históricas pregressas ligadas à história do sistema penal no Brasil. Este artigo intenciona fazer uma história do passado nos termos do presente (FOUCAULT, 1987, p. 29). Um "presente ao qual pertencemos" (FOUCAULT, 1989, p. 104-105) e que nos leva a questionar arranjos compartilhados e naturalizados. Sob esta perspectiva, a pesquisa assume suas imbricações ligadas à história do tempo presente, colocando sujeito e objeto 


\section{Um filme, um Museu, um Memorial... ressonâncias e encantamentos Elementos históricos e demandas sociais}

Entre os espaços simbólicos ligados às lembranças, a história da tragédia prisional que marca o Carandiru vem sendo apreendida de diferentes formas. Através de uma breve pesquisa na internet é possível facilmente elencar uma vasta produção editorial, audiovisual, museológica, entre outras, responsável por articular elementos históricos e demandas sociais vindas de diversos setores da sociedade civil e do Estado. Conforme a reportagem que abre o presente artigo: "Ao justificar o voto, ele (o desembargador) tentou reescrever a história. Não houve massacre, houve legítima defesa, afirmou". A história do massacre ainda está sendo escrita, um tecer que escapa ao pesquisador, um passado que vem sendo constantemente ressignificado.

Ao afirmar legítima defesa, o desembargador contradiz uma série de documentos oficiais amplamente divulgados em meio digital e de acesso público à população, como o Parecer Médico Legal, que concluiu que houve intencionalidade de matar, visto que os disparos dados pelos policiais se concentraram principalmente na região do tórax e da cabeça, informação essa amplamente difundida nas redes sociais através de memes, de forma quase concomitante à divulgação da nova decisão judicial através da imprensa. $O$ Laudo do Instituto de Criminalística da Polícia Científica, que afirma que a atuação policial visava a morte ou a incapacitação imediata das vítimas e ainda informações do Laboratório de Medicina Legal, da Universidade Estadual de Campinas, que corroboram essa informação (PEDROSO, 2012)․ A disponibilização desses documentos ao público ajuda a tecer a história do massacre, fornecendo instrumentos para o debate público.

A história do massacre vem sendo construída em vários lugares: relatos de sobreviventes e testemunhas, publicação de livros, músicas, documentários, peças de

\footnotetext{
7 Documentos diversos como o inquérito policial civil, fotografias e processos administrativos, processos internacionais, laudos, processos de responsabilidade civil, sentenças do tribunal do juri, depoimentos e inquérito policial militar, estão disponíveis na internet na página: $<$ http://www.massacrecarandiru.org.br/post/lista-de-materiais-disponiveis-nesta-plataforma>.
} 
teatro, exposições, filmes, séries de TV, eventos e artigos acadêmicos, etc. Esses lugares entrelaçam memória e história, instituem lugares de memória "nos três sentidos da palavra, material, simbólico e funcional, simultaneamente". Lugares marcados por uma multiplicidade, que podem ser "oferecidos pela experiência concreta", ou como lugares abstratos; lugares "portáteis", ou "topográficos", ou ainda "monumentais" e "arquiteturais" (NORA, 1993, p. 21-22). Nesse processo, a tragédia vem sendo constantemente revisitada, permitindo que novos sentidos sejam atribuídos a esse passado por diferentes segmentos sociais (GROOT, 2016). Da música Haiti Haiti (Caetano Veloso, 1993), aos livros Estação Carandiru (Drauzio Varella, 1999) e Diário de um detento (Jocenir, 2001), passando pelo sucesso estrondoso de Carandiru: o filme (Hector Babenco, 2003), muito já foi produzido a respeito do Carandiru ao longo desses 24 anos do massacre ${ }^{8}$. Esse movimento marca uma vontade de memória em conflito constante com uma intenção de apagamento, compondo uma teia complexa de relações de poder e enfrentamentos responsáveis por tecer esse passado no presente.

No artigo Massacre do Carandiru: Inação, Descontinuidade e Resistências (RODRIGUEZ et al., 2015, p. 92), as autoras relatam que em 2013, frente à possibilidade de utilização de recursos audiovisuais no decorrer dos depoimentos e dos debates em uma das sessões do julgamento do massacre, o Ministério Público autorizou a exibição de um trecho do filme Carandiru, de Hector Babenco. Os 10 minutos finais do filme foram projetados com áudio potente. Conforme as autoras:

\footnotetext{
${ }^{8}$ Não se intenciona aqui esgotar o tema, apenas citar alguns trabalhos inspirados no massacre para evidenciar a magnitude do trabalho de apreensão desse passado traumático. São muitos os relatos de sobreviventes e testemunhas que resultaram em publicações, principalmente no início dos anos 2000 como (RODRIGUES, 2002), (ZENI, 2002), (BISILLIAT, 2003), (RAMOS, 2001). Livros com imagens do Carandiru e do cotidiano dos presos (CASARIN, 2013). Também é possível, facilmente, citar algumas múcicas como Diário de um detento (Racionais MC's, 1997); Casa cheia (Detentos do Rap, 1998); Terror no Carandiru (autor desconhecido, 1993); Carandiru da morte (Pedro Anderson, sem data), além de Manifest (Sepultura, 1992). O episódio rendeu também documentários premiados, como Entre a Luz e a sombra (2009) e O prisioneiro da grade de ferro (2014). Em 2013, um site especializado em fornecer material para pesquisa escolar destinado principalmente a professores em busca de material para suas aulas, publicou um quizz de perguntas e respostas com a seguinte proposta: "Teste sua memória sobre o massacre do Carandiru". O teste relembra dados como o número de mortos, a lentidão da justiça em condenar os envolvidos, além de outros aspectos importantes como o fato dos rebelados não terem feito reféns. Utilizando-se de um recurso didático, o site rememora o massacre, retomando informações fundamentais para compreender a dimensão da tragédia. Ver: <http://educacao.uol.com.br/quiz/2013/10/02/teste-sua-memoria-sobre-o-massacre-do-carandiru.htm>.
} 


\begin{abstract}
À diferença dos demais julgamentos nos quais o juiz autorizou que os réus deixassem a posição simbólica do banco dos réus e se sentassem na plateia para assistir ao julgamento, naquele primeiro estavam todos no palco, de costas para a parede em que se projetava o filme de Hector Babenco. Alguns permaneceram impassíveis. Outros torciam pescoço para acompanhar a cena - seria a primeira vez que assitiam ao filme? Nunca saberemos a extensão do impacto desta narrativa audiovisual na formação da convicção dos jurados, mas nós, que estávamos presentes, vivenciamos um dos momentos mais impactantes de todo o julgamento.
\end{abstract}

O trecho em questão mostra da entrada da Polícia Militar no Pavilhão 9 até o término da operação. De acordo com as autoras, a exibição de parte do filme teria sido um dos momentos mais impactantes de todo o julgamento, elas tiveram suas experiências marcadas por essa formas de transmissão do passado (GROOT, 2016). A potencialidade do filme de Babenco aparece como instrumento fundamental, servindo nessa ocasião para potencilizar os sentidos tecidos para o episódio durante o julgamento. Exibir o trecho final, que mostra a invasão da polícia e a chacina dos detentos contribui para uma reatualização constante da memória do massacre.

Groot (p. 26, 2016), citando o trabalho de Robert Rosenstone (2013), argumenta que filmes populares teriam o potencial de ampliar o conhecimento histórico, influenciando o imaginário e a forma como as pessoas lembram de determinados fatos. A exibição do filme de Babenco em uma das sessões de julgamento parace atender à função de prova, contribui para a tessitura de uma sensação de proximidade com o que "realmente" teria acontecido no dia 2 de outubro de 1992. O passado pode ser sistematicamente reconfigurado a partir dos traços que ele deixou para trás (GROOT, 2016). Dessa forma, o filme, baseado em fatos reais, atua de forma semelhante à história, trabalhando com vestígios possíveis dentro de um passado que já não existe mais, cujo acesso não nos é possível por completo, mas cujos fragmentos atestam a exitência, provam o ocorrido.

Muitos elementos presentes no filme estão de alguma forma representados no Museu que guarda os vestígios do Carandiru. Em 2014, o Museu Penitenciário Paulista passou a funcionar em nova sede, localizada nas dependências do antigo Complexo do Carandiru, incorporando também um novo acervo: vestígios deixados pelos presos da antiga Casa de Detenção. Lá, podemos encontrar as facas, objetos corantes e armas 
confeccionadas pelos detentos, objetos em que engenhosamente escondiam drogas, elementos ligados à religiosidade, a engenhoca usada para fabricar a "maria louca" (um tipo de aguardente) e muitas teresas (cordas fabricadas pelos detentos a partir do material que encontravam na prisão: lençóis, roupas, etc.). São vestígios de criações proibidas, resistências frente aos limites institucionais, elementos presentes também no filme de Babenco. Os objetos expostos extrapolam os limites formais, despertam em quem os vê forças complexas e dinâmicas que possibilitaram suas existências; podem ser tomados pelo espectador como metáforas. São metáforas da vida na cadeia, do poder de criação frente aos limites impostos pelo confinamento. Eles causam encantamento, chocam, arrebatam quem os observa em uma miríade permeada por um misto de fascinação e medo, trasmitem um sentimento arrebatador de intensidade (GREENBLAT, 1991, p. 250).

O Museu foi criado em 1939, passando por diversas alterações ao longo dos anos, consolidando-se na década de 1960, quando uma comissão foi designada para organizar o espaço.

\begin{abstract}
A intenção do Museu Penitenciário Paulista é de produzir informações e conhecimento sobre a ciência jurídica penal e sua execução, observada na própria história do Sistema Penitenciário Paulista, assim como abordar suas características, desenvolvimento e evolução. Sua missão é ser um espaço aberto ao público em geral, capaz de propiciar a reflexão sobre a história penitenciária e a pena. ${ }^{9}$
\end{abstract}

Ao exibir o acervo referente ao Carandiru e contar a história do sistema Peniteniciário de São Paulo, o Museu cria metáforas sobre o espaço prisional. Contudo, são metáforas apaziguadoras, que parecem procurar a regeneração. De todos os elementos presentes no filme de Babenco possíveis de serem identificados no Museu, certamente o mais emblemático, o massacre, é tratado de forma velada. Se, no tribunal do Juri, os 10 minutos finais do longa, marcados pela invasão da polícia e pela sangrenta tomada do Pavilhão 9, chocaram alguns presentes, no Museu é como se essa parte fosse suprimida. Somente ao final da exposição, o espectador se depara com um banner que explica a desativação da Casa de Detenção e do "motim" de 1992. Na descrição, não é

\footnotetext{
${ }^{9}<$ http://museupenitenciario.blogspot.com.br>. Acessado em 01/08/2016.
} 

tumulto que culminou com a invasão da Polícia Militar. Esse episódio respercutiu em nosso país e mesmo no mundo todo. É tema de livros, filmes e músicas". Entre as escolhas possíveis para a rememoração, o Carandiru é apontando como "lugar histórico para o Sistema Penitenciário Paulista", "um marco do universo prisional brasileiro, tanto no seu sentido jurídico-policial quanto no seu aspecto simbólico, cultural e social". Contudo, as motivações que produzem esses sentidos não são mencionadas, a memória do massacre é, assim, uma ausência dentro da proposta do Museu.

No Brasil são poucos os Museus e/ou memoriais de prisão a pensarem o espaço prisional sob a perspectiva do patrimônio cultural, como parte da história e do tecido urbano das cidades; essas discussões ainda esparsas. Nos Estados Unidos, a história pública vem se debruçando sobre questões como encarceramento em massa e provocando a reflexão sobre os Museus de Prisão. No site da Eastern State Penitentiary ${ }^{10}$ é possível ter acesso a uma lista que divulga os aproximadamente 100 museus-prisões existentes no mundo, cerca de 40 destes só nos EUA; a lista deixa de fora o Brasil. Nos Estado Unidos, os historiadores públicos começaram a refletir sobre essa realidade. Em publicação recente, a historiadora Heather Ann Thompson (2010) fez uma provocação, convocando os colegas a esse esforço: “É hora de historiadores pensarem criticamente sobre o encarceramento em massa e começarem a considerar as repercussões deste fenômeno nunca antes visto" (p. 705).

Questões como o encarceramento em massa aproximam Brasil e Estados Unidos ; mais do que isso, tanto aqui quanto lá, o Estado

não tem sido capaz de assegurar os requisitos básicos para o encarceramento dos indivíduos. Os presos, independentemente de sua periculosidade, idade, reincidência, tipo de crime, são recolhidos em estabelecimentos, em geral, lotados, em condições sanitárias ruins, mantidos misturados desde o período em que permanecem no aguardo do julgamento até o período pós-julgamento. (SALLA, 2006b, p. 287)

\footnotetext{
${ }^{10}<$ http://www.easternstate.org/node/608>. Acessado em 09/09/2016.
} 
Nos Estados Unidos, o encarceramento em massa vem suscitando uma série de debates sobre a criação dos Museus de Prisão. Para além da preservação das edificações (que por lá geralmente datam do século XIX a meados do século XX), os historiadores estadunidenses têm questionado como a preservação dessa história pode contribuir para incitar a reflexão sobre a realidade prisional no país (BRUGGEMAN, 2012) ${ }^{11}$.

Um dos museus-prisões mais conhecidos do mundo é o de Alcatraz, lugar em que a violência é apresentada como um espetáculo descontextualizado do passado, mostrando a instituição e sua história como exceções. Os detentos são colocados como os outros, os diferentes; o contraste com eles torna-se a base para uma unidade frágil e precária entre a sociedade "normal" e ajustada e os "outros", os desviantes, colocados à distância daquilo que acreditamos ser a nossa essência. Nesse sentido não há silenciamento, mas uma espetacularização que se perde no vazio.

No Brasil, essas questões ainda aparecem timidamente, mas certamente merecem ser pensadas. No que se refere aos Museus ou espaços de memórias em Penitenciárias brasileiras, cabe citar o Museu Penitenciário (em SP), o Museu do Cárcere (RJ) ${ }^{12}$ e o Memorial da Penitenciária de Florianópolis (SC) ${ }^{13}$. Outros estados estão pensando em espaços de memória, como Paraná, Rio de Janeiro, Mato Grosso e Pernambuco. O trabalho realizado por Myriam Sepúlveda dos Santos (2005) na implementação do Ecomuseu Ilha Grande foi um dos pioneiros em buscar preservar a memória de práticas de violência e de arbitrariedade ética e moral, que são ou estereotipadas ou totalmente ignoradas pela sociedade. Conforme a autora:

O maior desafio enfrentado pelo Ecomuseu Ilha Grande diz respeito à preservação da história de um sítio que se tem procurado reiteradamente apagar da memória. O presídio foi demolido por duzentos quilos de dinamite por ordem do governador Nilo Batista, em abril de 1994, fato que repete medida similar tomada por ocasião da desativação da Colônia Penal Cândido Mendes, situada próximo à Vila do Abraão, também na Ilha Grande, em 1962, durante o governo Carlos Lacerda. Essas destruições podem ser consideradas como tentativas de apagar as memórias prisionais do país. (SANTOS, 2005, p. 394)

\footnotetext{
${ }^{11}$ A respeito da história pública e sua preocupação com a história das prisões ver também: (STRANGE, 2003), (WILSON, 2008), (SMITH, BERGMAN, 2010), (THOMPSOM, 2010), (MORRISSEY, SCHWARZER, 2011), (WELCH, 2015).

${ }^{12}$ Ver: (SANTOS, 2005).

${ }^{13}$ Ver: (BORGES, 2014).
} 
A ausência de discussões e políticas de preservação relacionadas ao patrimônio carcerário $^{14}$ no Brasil vem conduzindo ao desaparecimento de importantes edificações. Da mesma forma que o presídio da llha Grande, outros espaços prisionais foram apagados ao longo da história. Sem pretender esgotar o tema, cito como exemplos o Complexo Penitenciário Frei Caneca (1850, RJ), o Presídio de Tiradentes (SP, 1930), o Carandiru (1956). Outros tiveram parte de suas edificações postas abaixo, como o Presídio Central de Porto Alegre (RS, 1940) e Presídio do Ahú (PR, 1903). E de alguns só restam ruínas, como o da Ilha Anchieta (SP, 1902).

O Compexo Penitenciário Paulista, conhecido como Carandiru, começou a ser construído na década de 1920, com a criação da Penitenciária do Estado. A partir da década de 1950, numa tentativa de desafogar a instituição, que desde a década de 1940 vinha sofrendo com a a superlotação, foi construída, junto à Penitenciária do Estado, a Casa de Detenção (1956), a Penitenciária Feminina (1973) e o Centro de Observação Criminológica (1983), formando o popularmente conhecido Complexo Penitenciário do Carandiru.

O Carandiru chegou a ter oito mil detentos, excedendo sua capacidade em $200 \%$. Construído para abrigar menos de três mil presos, no dia 2 de outubro de 1992, haviam

${ }^{14}$ Enquanto os Estados Unidos procupam-se com os Museus de prisão e as potencialidades desses espaços para a discussão do encarceramento em massa (BRUGGEMAN, 2012), na França a discussão se refere mais a preservação das edificações. A expressão "patrimônio carcerário" é utilizada pelos franceses. Ela ganhou força recentemente na França, através de iniciativas como a realização do Colloque L'architecture carcérale, des mots et des murs, organizado em 2010 pela Ecole Nationale d'Administration Pénitentiaire, e de publicações como a obra intitulada "Prisons: Patrimoine de France" (2013), que traz 2500 fotos de prisões francesas, destacando as marcas deixadas pelos presos como desenhos, pinturas e escritas em paredes e edificações. A abertura para visitação da Prison de La Sante, em Paris, durante as Jornadas do Patrimônio francês de 2014, marcou definitivamente a emergência do tema dentro das discussões ligadas ao patrimônio cultural na França. Em 2016, a Revista Crimino Corpus publicou o dossiê Patrimoine Et Architecture Carcérale, com artigos que tratam do tema na França e na Suíça. A necessidade de preservar o patrimônio relacionado às prisões deve ser etendida não apenas em sua dimensão edificada, mas sob uma perspectiva mais ampla e difusa, envolvendo aspectos imateriais e materias. Nesta perspectiva, entendo o patrimônio carcerário a partir de três perspectivas interligadas. Trata da preservação da memória dos sujeitos envolvidos no cotidiano prisional: os sentenciados, seus familiares e os funcionários das instituições, problematizando a dimensão imaterial da experiência prisional, suas rotinas e suas práticas cotidianas. Envolve, ainda, a preservação dos acervos prisionais, documentais e/ou objetos tridimensionais: prontuários de presos, livros de registro, fotografias, cadeiras de identificação, uniformes, móveis e utensílios, incluindo aqui as "criações proibidas dos presos", vestígios por estes deixados durante o período de reclusão. A preservação destes acervos por parte das instituições nem sempre ocorre de forma adequada, implicando na perda de fontes importantes para pensar a história das prisões no Brasil e suas especificidades nos diferentes estados da federação. 

permanecendo na instituição junto com doentes mentais, detentos de alta e baixa periculosidade, todos misturados, além da carência de funcionários, gerando violência, motins, homicídios, corrupção, abuso sexual, tráfico de drogas, corrupção (DIAS, 2014), (TEIXEIRA, 2006).

Em 2001, um ano antes da implosão dos pavilhões do Carandiru, o município de São Paulo tombou o Conjunto de Edifícios da Penitenciária do Estado: a Casa do Administrador (da década de 20) e da vegetação remanescente da mata atlântica, "considerando o interesse artístico e histórico de elementos arquitetônicos e paisagísticos do denominado COMPLEXO PENITENCIÁRIO DO CARANDIRU" - ficando de fora as edificações da década de 1950, local do massacre, demolido em $2002^{15}$.

Em 2002, quando o massacre completou dez anos, o Carandiru foi desativado por completo; os presos foram transferidos para penitenciárias no interior do estado. E em 8 de dezembro desse mesmo ano, foram implodidos os pavilhões 6,8 e 9, sendo este último o local do massacre. Destruir parte das edificações de um espaço prisional que por quase cinquenta anos foi considerado o maior da América Latina, cenário de um massacre conhecido nacional e internacionalmente, evidencia uma tentativa de silencimento. Conforme veremos, somente dois pavilhões foram reinseridos na dinâmica da cidade, ganhando novos usos, ainda que totalmente descaracterizados e com tímida referência à história que marca o lugar.

O apagamento dos vestígios físicos relacionados ao Carandiru é corroborado por um dos novos usos do espaço: o Parque da Juventude. Construído para apagar uma "má memória", o Parque possibilita a prática de esportes e momentos de lazer sob uma "atmofera bucólica". Dispõe ainda de uma ampla biblioteca (4.257 $\mathrm{m}^{2}$ de área e cerca de 30 mil itens) e duas escolas técnicas (Escolas Técnicas Estaduais/Etec Parque da

\footnotetext{
${ }^{15}$ O processo de tombamento estadual, aberto pela Resolução 15/01 do CONDEPHAAT (Conselho de Defesa do Patrimônio Histórico Arqueológico, Artístico e Turístico de São Paulo), está em instrução e ainda não foi concluído.
} 
Juventude e de Artes) $)^{16}$. No site da Prefeitura de São Paulo é possível encontrar uma tímida menção referente às antigas funções do local onde hoje existe o Parque:

Construído no lugar da antiga Casa de Detenção de São Paulo, popularmente conhecida como Carandiru, o Parque da Juventude foi inaugurado em 2003, e é um dos locais mais frequentados da zona Norte da capital. É um complexo esportivo, cultural e recreativo de $240 \mathrm{mil} \mathrm{m}^{2}$, com uma estrutura mais do que completa. ${ }^{17}$

Tanto no site, quanto em seu espaço físico, não há nenhuma menção ao massacre. $\mathrm{A}$ mudança de paisagem promovida pelo Parque é um trabalho de regeneração da memória, possibilitando a reabilitação de um espaço anteriormente estigmatizado. Dentro do Parque, um dos únicos vestígios que restam da estrutura física do Carandiru, a muralha de pedra de 600 metros que permitia que os agentes vigiassem os presos, aparece dissociada da história do lugar e da dimensão da tragédia ali ocorrida. Tomada apenas pela curiosidade que desperta, as ruínas da antiga Casa de Detenção geram uma espetacularização que não estabelece uma conexão entre o passado e o presente.

O estigma da penitenciária até chegou a criar rejeição em outros tempos. Atualmente, só colabora para atrair pessoas. Principalmente por causa de uma muralha de 600 metros: era de lá que os seguranças vigiavam os internos. "Muitas pessoas evitavam nos visitar pela imagem negativa do presídio. Mas esse ponto específico virou uma atração"18.

A imagem "negativa" virou uma atração, o estigma da Penitenciária acaba por atrair os visitantes. A visitação ao local do massacre exige reflexão, pois envolve questões morais delicadas. A morbidez ou o medo que exercem podem despertar um fascínio a debater-se no vazio, que garante a sobrevivência da tragédia, mas completamente esvaziada de sentido político. Visitações a espaços ligados ao sofrimento e à morte, denominadas de dark tourism, (FOLEY e LENON, 1996), (LOGAN, 2009), tanaturismo (SEATON, 2002) ou turismo mórbido (BLOM, 2000), apenas recentemente tornaram-se uma preocupação de estudos acadêmicos, sendo ainda muito incipientes estudos que

\footnotetext{
${ }^{16}$ <http://vejasp.abril.com.br/materia/santana-parque-da-juventude>. Acessado em 31/12/2015.

17 <http://www.cidadedesaopaulo.com/sp/br/o-que-visitar/atrativos/pontos-turisticos/4388-parque-dajuventude>. Acessado em 31/12/2015.

${ }^{18}$ <http://museupenitenciario.blogspot.com.br/2012/12/no-ano-que-se-aproxima-apresentaremos.html>. Acessado em: 31/05/2015.
} 
A Escola Técnica Estadual (Etec) Parque da Juventude ocupa os únicos dois pavilhões que restam do antigo Carandiru. O lugar deu início as suas atividades em fevereiro de 2007, quando o massacre completou 15 anos, e abriga o Espaço Memória do Carandiru. A escola é apresentada de forma semelhante, como um projeto inovador e aberto, fazendo um contraponto com a antiga instituição que lá havia, representando, portanto, o seu oposto.

Ocupando uma área de cerca de 6000 mil metros, num prédio (re)construído sob a ótica de um projeto inovador e aberto, em contraposição a ocupação inicial (Casa de Detenção), a Etec 'Parque da Juventude', dispõe de 15 salas de aula ambientadas de acordo com o componente curricular $\left[\ldots . . .^{19}\right.$

O Espaço Memória do Carandiru, localizado nas dependâncias da escola, foi instituido através do Decreto estadual $n^{\circ}$ 52.112, de 30/8/2007, e encontra-se fechado. Conforme o documento, o Espaço tem como objetivos :

I - oferecer ao público em geral informações de caráter histórico, social e cultural sobre o Carandiru, organizadas em exposição permanente e em exposições temporárias;

II - propiciar, a estudantes e estudiosos, programações específicas relativas à memória do Carandiru;

III - desenvolver trabalho educativo junto à população em geral.

Constituído através de decreto e com funções delimitadas por este, o Espaço, de forma semelhante ao Museu Penitenciário, institui a memória oficial do ocorrido. A busca em oferecer ao público informações de "caráter histórico", confere um sentido de autenticidade à memória ali preservada e produzida. As informações localizadas no site não deixam claras as circunstâncias do ocorrido em 2 de outubro de 1992, procurando, em tom apaziguador, dar voz a vítimas e algozes. Através de uma narrativa conciliadora, é

\footnotetext{
${ }^{19}$ <http://vejasp.abril.com.br/materia/santana-parque-da-juventude>. Acessado em: 23/11/2105.
} 
Questões como a impunidade e a lentidão do julgamento dos policiais envolvidos são tratadas de forma velada pelo Memorial. Um dos casos mais controversos, o do Cel. Ubiratan Guimarães, comandante de Policiamento Metropolitano da PM, responsável por chefiar a operação é mencionado de forma cuidadosa: "O Cel. Ubiratan Guimarães era comandante de Policiamento Metropolitano da PM e chefiou a invasão. Foi um dos 86 policiais julgados. Foi condenado, obtendo a sentença de 632 anos de prisão, mas aguardou em liberdade seu pedido de recurso. Foi eleito deputado estadual, em 2002". O texto não menciona que o Coronel aguardou em liberdade até ser assassinado em 2006. Outros dados relevantes ficam de fora, como o fato de Guimarães ter sido eleito deputado pelo PSD, com o emblemáticonúmero 14111, o que remete aos 111 mortos no massacre. Na sequência do texto, o cartáter apaziguador torna-se ainda mais evidente, relativizando a condenação do Coronel, ainda que apontando a posição dos grupos de direitos humanos a esse respeito : "19 anos depois o caso ainda é alvo de controvérsia. De um lado, o chefe da operação diz que agiu no estrito cumprimento do seu dever. Do outro, grupos de direitos humanos acreditam que houve intenção de exterminar os presos e reclamam que ninguém foi punido". ${ }^{20}$

Na publicação Carandiru não é coisa do passado (RODRIGUEZ et al. 2015, p. 25) ${ }^{21}$, Ines Virginia Prado Soares e Paula Bajer Fernandes Martins sugerem como estratégia de reparação simbólica às vítimas do massacre a construção de "um lugar de memória" dentro do Parque da Juventude, "onde se abordaria o massacre, suas causas e circunstâncias", que indicasse o compromisso do Estado na não repetição da tragédia. As autoras paracem fazer referência à noção de reparação em um sentido amplo e difuso, uma abordagem que se aproxima do direito internacional, ligada aos diversos tipos de

\footnotetext{
${ }^{20}$ <http://www.cursophd.com.br/unidade/135>. Acessado em : 23/11/2015. Em 2014, 21 anos após o massacre, foram condenados os últimos 15 Policiais Militares indiciados. Ao todo, 73 policiais foram condenados por 77 mortes, 3 foram absolvidos. Eles receberam penas que variam de 96 a 624 anos de prisão. A respeito da responsabiblização do massacre ver (FERREIRA, MACHADO, 2012).

${ }^{21}$ A publicação teve seu lançamento em 2 de outubro de 2015, em meio a mais um ato de rememoração do massacre, seguido de um longo debate com os autores.
} 
museus e parques dedicados à memória das vítimas etc.” (GREIFF, 2010, p. 44). Sob a perspectiva dos direitos humanos, a criação de um local de rememoração ligado ao massacre deveria contemplar as vítimas, jamais os algozes. Certamente é essa a razão do Espaço Memória Carandiru e do Museu Penitenciário não terem sido mencionados na publicação citada acima. Esses lugares objetivam a construção de determinada memória "oficial" do massacre e, certamente, procuram atuar no sentido de reparação ; contudo, a maneira conciliatória, que dá voz a vítimas e algozes, não promovendo discussão mais direta que responsabilize o estado pelo ocorrido, impede a capacidade de redenção.

O processo de construção de memórias ligadas ao massacre é muito mais complexo que a dicotomia "memória oficial" versus "memória não oficial". A porosidade entre estas duas facetas, que se contradizem e se interpelam, desvelam contornos ligados a aspectos subjetivos que extrapolam a proposta do presente artigo. O Museu Penitenciário, por exemplo, é constantemente visitado por ex-detentos, alguns deles motivados pela possibilidade de gravarem seus depoimentos, contribuindo com o projeto "Memória Oral do Sistema Penitenciário Paulista ${ }^{22 ", ~ o u ~ a i n d a ~ i m p u l s i o n a d o s ~ a ~ d o a r e m ~}$ objetos e fotografias. Essa procura evidencia a capilaridade de memórias e discursos tramados em relações de poder, um poder que se exerce sobre as coisas, capaz de modificá-las, utilizá-las, consumi-las ou destruí-las (FOUCAULT, 1995, p. 240). Pesquisando no Museu em dois momentos distintos do ano de 2016, pude presenciar um exsentenciado que estava presente no dia do massacre, levando seu filho para conhecer a exposição. Em dado momento da visita, ele corrigiu a maneira como um objeto exposto havia sido montado, a engenhoca que fabricava a "maria Louca", uma espécie de cachaça artesanal produzida em espaços de aprisionamento. Nesse mesmo dia, ele doou uma imagem de lemanjá, orixá feminino muito popular no Brasil, a qual segundo ele, havia

22 <http://www.sap.sp.gov.br/download_files/pdf_files/revista/revista-sap-dez-2014.pdf >. Acessado em 14/11/2016. O projeto grava depoimentos de ex-setenciados que tenham vivido no Carandiru, bem como depoimentos de autoridades ligadas ao sistema penitenciário, especialistas em segurança pública e pesquisadores ligados ao tema. 

passado. Meses depois, em minha segunda visita, a imagem em questão já estava no espaço de exposição, ou seja, o objeto foi avaliado pela comissão de aquisição de acervos da instituição, que aceitou a doação e as informações sobre sua procedência e, mais do que isso, permitiu que figurasse como parte da exposição. Nessa segunda incursão ao Museu, vi esse mesmo sujeito conduzindo alguns visitantes e fui informada pela guia que ele passou a atuar como monitor. Se por um lado, determinados segmentos socias cobram o posionamento do Estado frente à tragédia, apontando a ausência de um lugar de memória que possibilite a reconciliação com esse passado, outros sujeitos, que vivenciaram o ocorrido, parecem se sentir identificados no espaço tido como de memória oficial. A memória excede as tentativas de controle.

\section{Uma metáfora para novas tragédias}

A miríade de produções culturais que resiginificaram o massacre do Carandiru, constrasta com as estratégias de apagamento e/ou apaziguamento. Podemos perceber ressonâncias dessas duas perspectivas em diferentes segmentos sociais, os quais também atuam nas resignificações e usos dessa memória (LOWENTHAL, 2003).

Ao longo de mais de 20 anos, os aniversários do massacre são marcados pela participação de movimentos sociais, familiares de presos e vítimas da violência de Estado. Entre eles, cabe destacar a Rede 2 de Outubro, criada em 2011 por um conjunto de organizações, movimentos sociais e grupos culturais. O grupo, que adota a data do massacre como nome, tem promovido reuniões, seminários, debates e outras atividades com o objetivo de denunciar e refletir sobre as condições de encarceramento, sobre o caráter seletivo do sistema penal e prisional e sobre o uso da violência pelo Estado. A Rede partilhava a "percepção de que a dinâmica social que produziu o Massacre do Carandiru ainda continua vigente e segue fomentando massacres". ${ }^{23} \mathrm{O}$ trecho citado é de

\footnotetext{
${ }^{23}<$ https://memoriacarandiru.wordpress.com/complexo-penitenciario-carandiru/>. Acessado em : 13/11/2015.
} 
A Rede se mistura a outras organizações não governamentais, como a Pastoral Carcerária de São Paulo. Em 2012, quando a tragédia fez 20 anos, foi realizado um ato na Praça da Sé :

"O ato não é apenas um resgate da memória dos 20 anos do Carandiru, uma situação clara de que não esquecemos e não esqueceremos jamais do que aconteceu, mas é também uma denúncia pública sobre todas essas políticas de massacre das populações periféricas, pretas e pobres, que ainda acontece nos dias de hoje", disse Rodolfo Valente, advogado da Pastoral Carcerária em São Paulo e integrante da Rede 2 de Outubro. ${ }^{25}$

Os atos anuais procuram atuar no sentido de "resgatar" a memória do massacre, instituindo um dever de memória, uma dívida social a ser paga. Rememorar atualiza a tragédia, aproxima passado e presente, impulsiona a atribuição de novos sentidos, tornando a tragédia uma metáfora utilizada para identificar outras prisões superlotadas e com perigo potencial de episódios de violência e rebeliões, chamadas de "novos Carandirus".

A teia de discursos sobre o evento ecoa no presente através de enunciados que procuram representar o trauma. Observa-se que, ao longo dos 24 anos que se seguiram ao massacre, o discurso que pedia justiça e cobrava a punição dos responsáveis transformou-se em um discurso mais abrangente, que exige das autoridades soluções para a superlotação das prisões brasileiras, a fim de evitar "novos Carandirus". ${ }^{26} \mathrm{~A}$ utilização do massacre como metáfora para pensar novas possíveis tragédias em espaços prisionais atua como categoria fundamental no processo de rememoração da tragédia

\footnotetext{
${ }^{24}<$ https://rede2deoutubro.milharal.org/category/multimidia/>. Acessado em : 13/11/2015.

${ }^{25}<$ http://carceraria.org.br/pastoral-carceraria-lembra-20-anos-do-massacre-do-carandiru.html\#sthash .Je7bgCFj.dpuf>. Acessado em : 13/11/2015.

${ }^{26}$ Refiro-me aqui às inúmeras reportagens que enuciam o surgimento de "novos Carandirus". A exemplo disso, ver: http://noticias.r7.com/sao-paulo/com-prisoes-superlotadas-sp-cria-novos-carandirus09092014. Acessado em: 31/05/2015.
} 
site do Espaço Memória Carandiru aponta que a destruição do espaço físico do Complexo teria sido uma iniciativa do governo estadual de desmantelar a estrutura de comando do PCC. O PCC foi criado em 31 de agosto de 1993, um ano depois do masssacre, como uma resposta ao aumento da letalidade policial e aos motins e rebeliões com desfechos violentos que passaram a fazer parte do cotidiano do sistema prisional a partir da década de 1990 (DIAS, 2014). As primeiras aparições do PCC na imprensa datam de 1997, ganhando maior visibilidade a partir de 2001, através de uma megarrebelião simultânea em 29 unidades prisionais, passando então a ser reconhecido pelo governo.

O massacre simboliza o fracasso de uma política de humanização do sistema carcerário, marcada pelo uso da violência, um processo que teve seu desfecho trágico em 1992 (cf. Salla, 2006b, 2007).

Criado no interior do Anexo da Casa de Custódia de Taubaté, presídio que representava o que de mais arbitrário havia no sistema carcerário paulista, o PCC surge ancorado no discurso da união entre os presos como forma de luta contra a opressão perpetrada pelo Estado. (ALVAREZ, SALLA e DIAS, 2013, p. 74)

A constituição do PCC como uma resposta às violações de direitos humanos, citando textualmente o caso do Carandiru como estopim, como uma represália dos presos frente à inflexão por parte do Estado, é parte do discurso político do próprio comando. ${ }^{28} \mathrm{O}$ discurso político e ideológico utilizado pelo PCC fica evidente através da denúncia da violência do sistema carcerário representada através do massacre do

27 De forma análoga a este uso da tragédia, Andreas Huyssen (2000, p. 13) analisa o holocausto como metáfora para outras tragédias: "é precisamente a emergência do Holocausto como uma figura de linguagem universal que permite à memória do Holocausto começar a entender situações locais específicas, historicamente distantes e politicamente distintas do evento original. No movimento transnacional dos discursos de memória, o Holocausto perde sua qualidade de índice do evento histórico específico e começa a funcionar como uma metáfora para outras histórias e memórias".

${ }^{28}$ O PCC vem sendo estudado principalmente por pesquisadores da área da sociologia que apontam a necessidade de analisar a ambiguidade desse discurso que "fala em lealdade, solidariedade e união na luta contra as injustiças e a opressão dentro das prisões" e, ao mesmo tempo, impregnado por valores rígidos, prevê a pena de morte sem apelação ou julgamento para aqueles que não seguirem suas normas. A esse respeito ver: (ADORNO e SALLA 2007), 
A utilização de ferramentas como o YouTube para a divulgação de músicas encomendadas pelo PCC de dentro dos presídios, confere um amplo alcance às denúncias realizadas e atuam no trabalho de reatualização da memória do massacre, constantemente referido pelo Primeiro Comando. Em 2015, uma música encomendada pelo PCC ao rapper Cascão atingiu mais de 150 mil visualizações em 20 dias. ${ }^{30}$

Conforme citado anteriormente, a disponibilização de documentos relativos ao massacre na internet através da Plataforma Memória Massacre Carandiru ${ }^{31}$ amplia o alcance e fornece instrumentos para o debate público. O projeto tem como objetivo reunir documentos e materiais que possibilitem a reflexão sobre a tragédia, disponinilizando uma gama de fontes até então inacessíveis à pesquisa.

O projeto Memória Massacre Carandiru tem por objetivo resgatar e reunir digitalmente documentos e materiais sobre o episódio que ficou conhecido como o Massacre do Carandiru. Apesar de ter tido ampla repersussão na esfera pública nacional e internacional, a memória desse episódio está em risco. O local de tal violação de direitos humanos foi demolido e não há até agora qualquer iniciativa oficial de preservação e problematização dos fatos. (grifos da autora). ${ }^{32}$

O Projeto teve início através de uma pesquisa intitulada "Carandiru não é coisa do passado", remetendo à atualidade de um passado ainda presente. Além de documentos oficiais, citados anteriormente, o projeto propõe uma Plataforma Colaborativa que convida as pessoas a participarem, doando materias como fotografias, documentos, cartas, vídeos, etc. Um dos objetivos da Plataforma é também problematizar as condições atuais do sistema penal brasileiro, reforçando a memória do massacre como

\footnotetext{
29 “O Anexo da Casa de Custódia e Tratamento de Taubaté foi inaugurado em 1985, depois se tornou Centro de Readaptação Penitenciária. Era destinado a presos líderes de rebeliões, violentos, mantinha os presos em condições duras de encarceramento". (ADORNO, SALLA, 2007).

30 http://www.cartacapital.com.br/sociedade/pcc-encomenda-musica-e-manda-201csalve-geral201d3359.html.

31 O projeto foi proposto em 2015, uma parceria entre o Núcleo de Estudos sobre o Crime e a Pena, da Fundação Getúlio Vargas (FGV) Direito SP e a Associação Nacional de Direitos Humanos, Pesquisa e PósGraduação (Andhep).

32 <https://memoriacarandiru.wordpress.com/complexo-penitenciario-carandiru/>. Acessado em : 12/11/2015.
} 
metáfora para pensar novas tragédias. Nesse processo de rememoração, de tentativa de controle de uma perda durável, podemos observar um dever de memória que gera dispositivos, evidenciando a proeminência da memória como forma de gestão do passado ou representação deste.

\section{Considerações Finais}

Procurei problematizar uma questão atual sob a perspectica da história do tempo presente a da história pública, entendendo-as não como genêros historiográficos, mas como posições que permitem uma série de debates no campo da história do contemporâneo. Minha intenção foi a de tecer um embate dentro do difícil trabalho de apreender uma história ainda em curso, cujas reverberações transformaram o presente texto até o último momento. $\mathrm{O}$ artigo foi gestado até prazo limite para o envio, que ironicamente era a data do aniversário do massacre: 2 de otubro. Sendo assim, essas considerações seguramente não são finais. Estou tratando aqui de uma história inacabaca, com a certeza de que acontecimentos vindouros poderão mudar a análise proposta.

A história do tempo presente, centrada no século $X X$, muito tem produzido a respeito do trágico e suas memórias, histórias que não passam, que estão sempre presentes $^{33}$. Se nos Estados Unidos é possível observar uma preocupação dos historiadores em se posicionarem sobre o encarceramento em massa e o aumento da violência dentro das prisões, percebendo a urgência dessa demanda social ligada a um fenômeno jamais visto, no Brasil a entrada da história nesse debate ainda é tímida. A superlotação das prisões brasileiras nunca atingiu níveis tão alarmantes ${ }^{34}$, a violência prisional e seu ápice, o Carandiru, desvelam acontecimentos sem precedentes na História,

\footnotetext{
33 Ver: (AREND, 2009).

${ }^{34}$ Conforme o Levantamento Nacional de Informações Penitenciárias - INFOPEN, de junho de 2014, o Brasil ultrapassou a marca de 600 mil presos. De acordo com o documento, o país é a quarta maior população carcerária do mundo, ficando atrás apenas dos Estados Unidos, China e Rússia. Em recente Relatório divulgado pelo Ministério da Justiça, os dados revelados mostram uma situação alarmante: as 1.424 prisões que existem no país têm capacidade para 376.669 pessoas, mas recebem atualmente 607.730 presos. Ver: <https://www.justica.gov.br/noticias/mj-divulgara-novo-relatorio-do-infopen-nesta-tercafeira/relatorio-depen-versao-web.pdf >. Acessado em 19/11/2016.
} 
Cabe também aos historiadores pensar sobre o nosso próprio tempo, tentando criar uma reflexão que permita um recuo relativo, que conecte o passado pelo presente. Problematizar os espaços prisionais e suas práticas, cotejá-los com base em valores históricos, culturais, memoriais, não é um exercício simples. As demolições e o abandono das edificações convivem com tentativas de domesticação da memória, interpeladas por usos sociais que também instituem novos significados e apropriações que escapam de qualquer tentativa de controle. Procurei vislumbrar essas memórias em conflito, os jogos de interesses, as relações de poder, seus apagamentos e exclusões. Rememorar o passado, selecionar dele o que deve ser lembrando, não é algo natural, mas um processo que envolve seleção. A história do massacre do Carandiru tornou-se uma questão pública, uma história movediça, em pleno desenrolar, escrita através de uma profusão de materiais que a divulgam para um público cada vez mais amplo, atendendo as demandas sociais que desejam discutir o ocorrido.

Tratei aqui de um passado que não passa, de um enfrentamento entre uma tentativa de apagá-lo e uma vontade de agir sobre ele. Problematizar esse processo atende a uma impaciência social, obriga o historiador a refletir sobre experiências transmitidas com urgência. Frente a práticas instituicionais marcadas pela superlotação e violações de direitos humanos, o Carandiru não é coisa do passado, mas parte das preocupações do presente.

Creio que por essas razões, não apenas o ocorrido no Carandiru, mas o sistema penal e seus efeitos sociais, o encarceramento e suas práticas institucionais, são temas a serem tratados pela história. Demolir, varrer do tecido urbano esses marcos simbólicos não apaga as memórias que os cercam, elas seguem ressonando no debate público. E assim, respondo a apenas uma das questões proposta no início deste trabalho, ficando a outra pergunta: Como lidar com um passado marcado por uma história trágica, que desvela a degradação humana? E aqui acrescento outra inquietação: como pensar a memória relacionada às prisões? 


\section{Referências}

ADORNO, Sérgio. SALLA, Fernando. Criminalidade organizada nas prisões e os ataques do PCC. Estudos Avançados. vol.21, n.61, pp.7-29. ISSN 0103-4014, 2007.

ALVAREZ, Marcos César, SALLA, Fernando, DIAS, Camila Nunes. Das comissões de solidariedade ao primeiro comando da capital em São Paulo. Tempo Social : Revista de Sociologia da USP, v. 25, n. 1, 2013.

ALMEIDA. Juliene R. de. ROVAI, Marta G. de O. Introdução à história pública. São Paulo: Letra e Voz, 2011.

AREND, Silvia. MACEDO, Fábio. Sobre a história do tempo presente: entrevista com o historiador Henry Rousso. Tempo e Argumento. Florianópolis, v. 1, n. 1, p. 201-216, jan./jun. 2009.

BABENCO, Hector (Direção). Carandiru. Roteiro: Victor Navas, Fernando Bonassi e Hector Babenco. Elenco: Rodrigo Santoro, Milton Gonçalves, Luiz Carlos Vasconcelos, Maria Luiza Mendonça e Caio Blat. Brasil. HB Filmes e Globo Filmes, 2003. DVD, 147 min.

BÉDARIDA, François. Temps présent et présence de l'histoire. In: INSTITUT D'HISTOIRE DU TEMPS PRÉSENT. Ecrire l'histoire du temps présent. Paris: CNRS, 1993.

BISSILIAT, Maureen. (Org.) Aqui dentro páginas de uma memória: Carandiru. São Paulo: Imprensa Oficial, 2003.

BORGES, Viviane Trindade. O tempo abre as portas a quem sabe esperar: usos do passado e embates do presente no percurso da exposição realizada na Penitenciária de Florianópolis (SC). Revista Esboços. Florianópolis: UFSC, n. 31, 2014.

BLOM, T. Morbid Tourism: A Postmodern Market Niche with an Example from Althorpe. Norwegian Journal of Geography, 2000.

BRESCIANO, J.A. El tiempo presente como campo historiográfico: ensaios teóricos y estúdios de casos. Montevideo: Cruz del Sur, 2010.

BRUGGEMAN, Seth. Reforming the carceral past: eastern state penitentiary and the challenge of twenty-first century prison museums. Radical History Review, n.113, p. 17186, 2012.

CANCELLI, Elizabeth. Carandiru: a prisão, o psiquiatra e o preso. Brasília: Ed. UnB, 2005. 
CASARIN, Doug. Carandiru 111. 2. ed. São Paulo: Editora Senac, 2006.

CAUVIN, Thomas. Public history: a textbook of practice. New York: Routledge, 2016.

CHARTIER, Roger. A visão do historiador modernista. In: FERREIRA, Marieta de Moraes; AMADO, Janaína. Usos e abusos da história oral. Rio de Janeiro: Editora FGV, 2000. p.215218.

CHAUVEAU, Agnès; TÉTART, Philippe (Orgs.). Questões para a história do presente. São Paulo: EDUSC, 1999.

DIAS, Camila C. Nunes. Estado e PCC em meio às tramas do poder arbitrário nas prisões Tempo Social : Revista de Sociologia da USP, v. 23, n. 2, Data

DIAS, Camila Nunes.Consolidação do primeiro comando da capital (PCC) no sistema carcerário paulista e a nova configuração do poder. L'Ordinaire des Amériques, n.216, 2014. Mis en ligne le 11 juillet 2014, consulté le 02 avril 2016. Disponível em < http://orda.revues.org/1086>. Acesso em : 15/05/2016.

DOSSE, François. História do tempo presente e historiografia. Revista Tempo e Argumento: Universidade do Estado de Santa Catarina Florianópolis, v. 4, n 1, p. 5-23, jan./jun., 2012.

FERREIRA, Luisa M. A.; MACHADO, Marta R. de A. ; MACHADO, Maíra Rocha. Massacre do Carandiru: vinte anos sem responsabilização. Novos Estudos - CEBRAP [online], n.94, p.05-29, 2012. Disponpivel em : Acesso em : 28 de março de 2016. ISSN 0101-3300.

FERREIRA, Marieta de Moraes. História do tempo presente: desafios. Petrópolis: Cultura Vozes, 2000.

FOLEY, M. ; LENNON, J. JFK and Dark Tourism: afascination with assassination. International Journal of Heritage Studies, n.2, 1996.

FOUCAULT, Michel. Vigiar e punir: nascimento da prisão. Petrópolis: Vozes, 1987.

FOUCAULT, Michel. O que é o iluminismo. In: ESCOBAR, C. H. (Org.). Dossier Foucault. Rio de Janeiro: Taurus, 1989, p. 103-112.

FOUCAULT, Michel. Sujeito e Poder. In : DREYFUS, H. RABINOW, P. Michel Foucault, uma trajetória filosófica : (para além do estruturalismo e da hermenêutica). Vera Porto Carrero. Rio de Janeiro : Universitária, 1995. P. 231 - 249. 
FRANCO, Bernardo Mello. A nova vergonha do Carandiru. In: $<$ http://www1.folha.uol.com.br/colunas/bernardomellofranco/2016/09/1817475-a-novavergonha-do-carandiru.shtml>. Acessado em: 12/01/2015.

GREIFF, Pablo de. Justiça e reparações. Revista Anistia Política e Justiça de Transição. Brasília: Ministério da Justiça, n. 3, jan./ jun., 2010.

GROOT, Jerome. Consuming history: historians and heritage in contemporary popular culture. New York: Routledge, 2016.

GREENBLATT, Stephen. O novo historicismo: ressonância e encantamento. Estudos Históricos. Rio de Janeiro, v. 4, n. 8, p. 244-261, 1991.

HUYSSEN, Andreas. Culturas do passado-presente : modernismos, artes visuais, políticas da memória. Rio de Janeiro: Contraponto, 2000.

JOCENIR. Diário de um detento: o livro. São Paulo: Labortexto Editorial, 2001.

LAGROU, Pieter. A história do tempo presente na Europa depois de 1945: como se constituiu e se desenvolveu um novo campo disciplinar. Revista Eletrônica Boletim do TEMPO. Rio de Janeiro, Ano 4, n.15, 2009. Disponível em: http://www .tempopresente. <org/index.php?option=com_conten t\&task=view\&id=4882\&ltemid=147>. Acesso: $02 \mathrm{de}$ jul. 2009.

LOGAN, William; REEVES, Keir. Remembering places of pain and shame In: LOGAN, William e Reeves, Keir (Orgs.). Places of pain and shame: dealing with difficult heritage. London; New York: Routlegde, 2009.

LOWENTHAL, David. Tragic traces on the Rhodian shore. Historic Environment. v. 17, n.1. Australia: ICOMOS, 2003.

MAUAD, Ana et al. História pública no Brasil: sentidos e etinerários. São Paulo: Letra e voz, 2016.

MENESES, Ulpiano T. Bezerra. A história, cativa da memória? para um mapeamento da memória no campo das ciências sociais. Revista do Instituto de Estudos Brasileiros SP, n. 34, p. 9-24, 1992.

PEDROSO, Regina Célia. Abaixo os direitos humanos! A história do massacre de cento e onze presos na Casa de Detenção de São Paulo. Revista Liberdades. Publicação Oficial do Instituto Brasileiro de Ciências Criminais, n. 9. Jan./abr., 2012. 
PEDROSO, Regina Célia. Os signos da opressão: história e violência nas prisões brasileiras. São Paulo: Arquivo do Estado, Imprensa Oficial do Estado, 2002.

PORTO, Gilson (Org). História do tempo presente. Bauru: EDUSC, 2007

RAMOS, Hosmany. Pavilhão 9: paixão e morte no Carandiru. São Paulo: Geração Editorial, 2001.

RAP, André du. Sobrevivente André do Rap (do Massacre do Carandiru). São Paulo: Labortexto Editorial, 2002.

RICOEUR, Paul. A memória, a história e esquecimento. Campinas: EdUNICAMP, 2011.

RODRIGUES, Humberto. Vidas do Carandiru: histórias reais. São Paulo: Geração Editorial.

ROSENSTONE, R.; PARVULESCU, C. A companion to the historical film. Oxfor: WilwyBlackwell, 2013.

RODRIGUEZ et al. Massacre do Carandiru : Inação, Descontinuidade e Resistências. In: MACHADO Maíra Rocha, MACHADO, Marta Rodriguez de Assis (Orgs). Carandiru não é coisa do passado: um balanço sobre os processos, as instituições e as narrativas 23 anos após o massacre. São Paulo: FGV Direito SP, 2015. 552 p.

ROUSSO, Henry. A história do tempo presente, vinte anos depois. In: PORTO JR., Gilberto (Org.) História do tempo presente. Bauru: EDUSC, 2007, p. 277 - 296.

SANTOS, Myrian Sepúlveda dos. Os conflitos entre natureza e cultura na implementação do Ecomuseu Ilha Grande. Hist. cienc. saude-Manguinhos [online], v.12, suppl., p.381-382, 2005. Disponível em: < http://dx.doi.org/10.1590/S0104-59702005000400020>. Acesso: 02/07/2015, 2009. ISSN 0104-5970.

SANTOS, Myrian Sepúlveda dos. ARAÚJO, Paula. História, memória, esquecimento Implicações políticas. Revista Crítica de Ciências Sociais. v.79, Dez., 2007.

SANTHIAGO, Ricardo. Duas palavras, muitos significados: alguns comentários sobre a história púbica no Brasil. In: MAUAD, Ana. de. et al. História pública no Brasil: sentidos e etinerários. São Paulo: Letra e voz, 2016.

SALLA, Fernando. As prisões em São Paulo. São Paulo: Annablume : Fapesp, 2006a.

SALLA, Fernando. As rebeliões nas prisões: novos significados a partir da experiência brasileira. Sociologias, 16, 2006b. 274-307. 
SALLA, Fernando. De Montoro a lembo: as políticas penitenciárias de São Paulo. Revista Brasileira de Segurança Pública, 2007.

SARLO, Betariz. Tiempo presente: notas sobre el cambio de uma cultura. Buenos Aires: Siglo Veinteuno, 2001.

SEATON, A.V. Guided by the dark: from thanatopsis to thanatourism. International Journal of Heritage Studies, n.2,1996.

SMITH, Cynthia Duquette. BERGMAN, Teresa Bergman. You Were on Indian Land: Alcatraz Island as Recalcitrant Memory Space, from Places of Memory: The Rhetoric of Museums and Memorials. Local: University of Alabama Press, 2010, p.160-190.

STRANGE, Carol Strange. KEMPA, Michael. Shades of Dark Tourism: Alcatraz and Robben Island. Annals of Tourism Research. v.30, Issue 2, p. 386-405, abr., 2003,

STONE, Philip; SHARPLEY, Richard. Consuming dark tourism: a thanatological perspective Annals of Tourism Research, v. 35, n.2, 2008.

STONE, Philip R. Dark Tourism and significant other death. Towards a model of mortality mediation. Annals of Tourism Research, v. 39, n.3, 2012.

THOMPSON, Heather Ann. Why Mass Incarceration Matters: Rethinking Crisis, Decline, and Transformation in Postwar American History. Journal of American History., n. 97, p. 703-34, 2010.

TUNBRIDGE, John E.; ASHWORTH, Gregory J. Dissonant heritage: the management of the Past as a Resource in Conflict. Londres: Belhaven Press, 1996.

TEIXEIRA, Alessandra. Do sujeito de direito ao estado de exceção: o percurso contemporâneo do sistema penitenciário brasileiro. São Paulo, 2006. Dissertação (Mestrado em Sociologia) - USP, local, 2006.

VARELLA, Drauzio. Estação Carandiru. 24.ed. São Paulo: Companhia das Letras, 2002.

VARELLA, Flávia; MOLLO, Helena Miranda; PEREIRA, Mateus Henrique de Faria; MATA, Sérgio da (Orgs.). Tempo presente e usos do passado. Rio de Janeiro: FGV, 2012.

VELOSO, Caetano (1993) Letra de "Haiti". Música: Gilberto Gil. Letra: Caetano Veloso. Encarte de CD Tropicália 2, de Caetano e Gil. (Polygram). 
WELCH, Michael. Escape to prison:
University of California Press, 2015.

WILSON, Jacqueline. Prison: Public Memory and Dark Tourism. New York: Peter Lang Publishing, 2008.

ZENI, Bruno (Coordenação Editorial). O Massacre do Carandiru. In: AUTOR. Sobrevivente André du Rap (do massacre do Carandiru). São Paulo: Labortexto editorial, 2002. p.17-27 e 199-218. 